\title{
THOMAS PAVEL, Il sogno e la comunità umana in Balzac
}

\section{Marco Stupazzoni}

\section{(2) OpenEdition \\ Journals}

\section{Edizione digitale}

URL: https://journals.openedition.org/studifrancesi/45244

DOI: $10.4000 /$ studifrancesi.45244

ISSN: 2427-5856

\section{Editore}

Rosenberg \& Sellier

\section{Edizione cartacea}

Data di pubblicazione: 1 août 2021

Paginazione: 386

ISSN: 0039-2944

\section{Notizia bibliografica digitale}

Marco Stupazzoni, «THomas PAvel, I/ sogno e la comunità umana in Balzac», Studi Francesi [Online], 194 (LXV | II) | 2021, online dal 01 septembre 2021, consultato il 15 octobre 2022. URL: http://

journals.openedition.org/studifrancesi/45244 ; DOI: https://doi.org/10.4000/studifrancesi.45244

Questo documento è stato generato automaticamente il 15 octobre 2022.

\section{(c)}

Creative Commons - Attribuzione - Non commerciale - Non opere derivate 4.0 Internazionale - CC BYNC-ND 4.0

https://creativecommons.org/licenses/by-nc-nd/4.0/ 
THOMAS PAVEL, Il sogno e la comunità umana in Balzac

Marco Stupazzoni 


\section{NOTIZIA}

THOMAS PAVEL, Il sogno e la comunità umana in Balzac, trad. C. De Carolis, in Il Pensiero e

l'emozione. La rappresentazione del sogno nella letteratura a cura di A. Lavagetto, Pisa, Pacini Editore, 2019, «Studi di letterature comparate (seconda serie)» 28, pp. 125-142.

In questo studio, l'A. focalizza la sua attenzione sulle affinità tra le opinioni politiche di Balzac e quelle di Benjamin Constant, grande teorico del liberalismo francese, attraverso l'analisi della funzione svolta dal sogno in Les Deux Rêves, racconto che risale al 1830, un anno dopo la pubblicazione del saggio di Constant: De la littérature dans ses rapports avec la liberté.

2 Les Deux Rêves hanno come protagonisti diversi convitati riuniti a casa di Madame de Saint-James, moglie del tesoriere generale della marina sotto Luigi XIV. L'attenzione degli astanti è subito catturata dalla narrazione di due sogni: quello di un avvocato che lo ha messo in presenza di Caterina de' Medici; quello di un chirurgo (già ubriaco) il quale afferma di aver «rêvé le peuple! [...] Je soignais alors un malade auquel je devais couper la cuisse le lendemain de mon rêve» (p. 135). L'identità dei due sognatori è alla fine svelata: si tratta di Marat e di Robespierre i quali, raccontando le loro allucinazioni oniriche, «annunciano la svolta che prenderà la Rivoluzione» (p. 136). Tra la violenza e gli eccessi dell'Ancien Régime e quelli che segneranno il Terrore rivoluzionario, il passo è breve e la continuità è evidente. Nel racconto, la visione politica di Balzac si trova in sintonia con il liberalismo di Constant per quel che riguarda, in particolare, il rifiuto dell'assolutismo. In Les Deux Rêves, conclude Th. Pavel, i sogni «dell'avvocatello e del chirurgo ubriaco fradicio rivelano le emozioni e le passioni politiche dei due sognatori, e in particolare la loro ostilità verso l'individuo e la sua libertà» (p. 14). 